\title{
OPTIMIZATION OF DIGITAL MARKETING PROCESSES THROUGH MODELING OF LEAD-SCORING
}

Aleksandar Đorđević

Singidunum University,

Belgrade, Serbia
Correspondence:

Aleksandar Đorđević

e-mail:

adjordjevic@singidunum.ac.rs

\begin{abstract}
:
The primary purpose of this paper is to explore and identify the possibilities for optimizing of digital marketing activities through establishing valuesystems reflected in lead-scoring models. Methodologically, the paper was based on the conclusions of quantitative and qualitative research, largely through drawing conclusions through secondary research, but also through primary research based on experimental, empiric cases of using digital marketing software tools such as the ClickDimension - corporate CRM tool. The empiric part of the primary research was enabled through the author's practical experience as a marketing executive in an IT industry-leading Serbian and regional system-integrator company. Conclusions of this paper can positively influence practical application of marketing, namely CRM tools through which organizations can model their value-systems reflected in lead scoring, in order to best optimize their digital marketing efforts in an optimal utilization of their resources. Although this particular paper focuses on the use of a particular software tools, the methodology translates to other similar consumer-relationship-management tools used in practice as well, making its potential application broader and more relevant to marketing professionals and academic community.
\end{abstract}

\section{Keywords:}

business optimization, lead-scoring, modeling, campaign management, marketing management.

\section{INTRODUCTION}

It used to be considered as traditional that the marketing departments, in some medium and most large-sized companies, are the go-to address that uses certain analytics in order to better understand and predict customer behavior that leads towards their purchasing preferences. This approach, natively channeled through the activities of marketing departments, have given the companies an opportunity to gravitate towards the more frequent and more focused, highly targeted marketing campaigns rather than the bulk marketing campaigns.

With the recent technology development many processes - including the collection of relevant consumer information and models of their likely purchasing behavior - have been heavily automated. This has led to companies' reliance on the evolving modeling and optimization through 
some key-process automation. Such a positive evolution has allowed companies to carry out marketing analytics beyond marketing departments only, and empower their cross-functional teams which, by design, have a better position to feed into the company's value system to sibsutitude some of the traditionally marketing led analytics in order to optimize entire business functions.

Although such shared marketing analytics is more pronounced in a B2B oriented model, for the sole reason that B2B markets are typically smaller in size and consequentially easier to comprehend and oversee, the automation of the mentioned processes would also be possible for application a $\mathrm{B} 2 \mathrm{C}$ marketing, given the assumption that there would be a reasonably smaller number of targeted markets that share similar key characteristics.

Additionally, the amount and type of data collected by the content that users consensually leave behind themselves throughout use of social media, has changed the strategies of traditional marketing, providing an opportunity to address marketing from a new perspective [1].

\section{REVIEW OF THE MARKETING-LED PROCESS AUTOMATION}

The hereby presented core problem is in the fact that many of the inbound marketing-related problems find their organizational bottlenecks in the activities restrained by:

- the lack of relevant data,

- appropriate resources that would enable the position to process the mentioned data into a meaningful information,

- the lack of means to replicate the repetitive processes through a model of automated actions that need little to virtually no attention throughout the process, and

- the lack of know-how in managing the automation software streamlined towards general business optimization.

In author's professional experience, particularly in the IT industry, there is an apparent lack of focus on promotion activities towards the end-users targeted advertising. These last mile advertising challenges have been identified as a tangent problem in attracting and maintaining a segment of profitable consumers, and on the other hand to determine those factors that undermine this objective [2].
Strangely enough though, it is quite curious that many small companies globally are held below the bottom in the competing world regarding earning of profits compared with multinational companies mainly because of not employing modern techniques that digital marketing allows for. Consequently, these leads underline the need for a deeper study be undertaken to identify and highlight the probable benefits, attached deficiencies and managing options for the potential disadvantages of digital so that all-sized business, especially the small ones, could join the economic and business competition with the rapidly growing companies [3].

Just like automation software can pretty much circumvent a key business aspect such as warehousing, marketing process automation could potentially optimize company's resources in order to drive most efficiency out of company's resources. A good example of a business model that used model of heavy marketingprocesses optimization, in order to optimize the business holistically is known as "dropshipping". Dropshipping is a method of selling products in which the seller does not necessarily physically store them. This method usually generates more profit per unit sold due to the cost savings that occurs when retailers outsource the warehousing and distribution process [4].

Therefore, the core problem that exist is not if and who within the organization would be in best position to optimize the chosen CRM to best feed the marketing, cross-functional team leaders and members, or management with intel and inputs for future decision making in order to maximize business optimization.

The core problem that this research focuses on is the fact that any model of lead-scoring - and some sort of lead-scoring is necessary in order to be able to quantifiably set the KPIs - is a challenge that many of the business will find themselves in.

\section{Optimization of Marketing Processes With Use of Social Networks That Feed Data to CRM}

The first glance at one of the commonly accepted definitions of what CRM portraits, is that "CRM is a comprehensive and marketing strategy; that integrates technology, process and all business activities around the customer" [5], showcases the comprehensiveness of the scope of customer relations.

As Chi-Shen rightfully points out, transactional content defines four types of purposes for which people use social networks to communicate: 
1. exchange of affect,

2. exchange of influence or power,

3. exchange of information, and

4. exchange of goods and services [6].

A social network may have the characteristics of internal and/or external linkages, and people may not be equally important in the social network nodes in terms of the role they play [7].

As proscribed by Cox the inbound marketing manager faces the biggest obstacles in overcoming the process automation rely heavily on the lack of effective strategic guidance, fairly closely followed by the complexity of the system [8]:

Table 1. Perceived barriers in marketing process automation

\section{Most Significant Barriers to Marketing Automation Success}

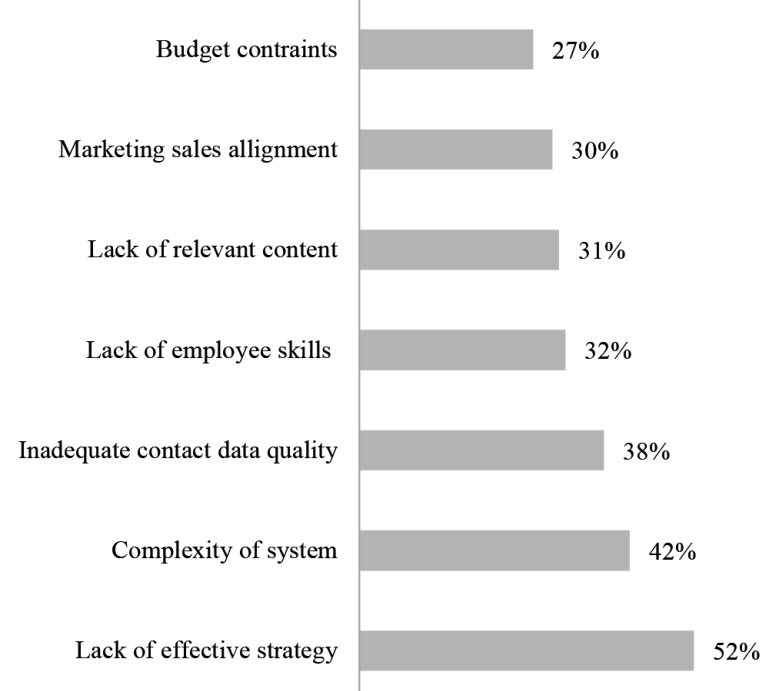

\section{PRACTICAL APPLICATION OF ALEAD- SCORING MODEL APPLIED TO A MARKETING CAMPAIGN}

It is safe to assume that the common denominator for most strategies, regardless of the industry at stake, would rely on utilizing available resources in a manner that is not easily or quickly replicable by the relevant competitors. Instead of the classic strategies approach which insisted that the organization responds to changes in the environment, through the strategy of "shaping" the organization seeks to shape the business environment in its favor, the shaping strategy is particularly applicable in varying industries, such as digital marketing, IT industry, fashion and other areas.
Contrary to the above, the classic strategies have greater success in traditional industries, such as automotive, oil, mining and other less volatile sectors [9]. Yet, the IT industry is one of the leaders of shaping the business in a automated manner, where the business organization tends to lean onto the software to do (at least) most of the repetitive tasks. One of the first dominoes in this structure is, however, the value system of an organization that needs to be shaped thoroughly.

This value system will later be reflected throughout all of the processes - especially the ones aimed at to be automated - and all of the systems outputs. Therefore, the question of how does an organization model the lead-scoring, in order for marketing activities to fulfill its key role (in many B2B organizations this role is to feed the presales or the sales teams)?

It is a well-established practice that marketing department defines the values for lead-scoring modeling, based on the:

1. business intuition and information from the presales and sales teams,

2. current market conditions,

3. type of the campaign aimed at targeting a specific group.

Some of the good experiences with lead scoring, reflected some common values and were drawn from:

- marketing's experience about the effectiveness of particular channels that has led to actual conversions

- the aspects that express a deeper involvement should naturally be scored higher in the model

- cross-functional teams consisting of both sales and marketing employees should give inputs through several iterations of campaign management, especially in the retargeting stages of the campaign

It is critical that the CRM is fed not only from the digital sources, but also from the offline points of interaction with the leads, especially considering that the modeled lead-scoring is supposed on bettering organizational processes for developing valuable and timely content to meet customer needs and for integrating content marketing whit B2B selling processes [10].

Process automation through use of a particular software

In an empirical research, observing an actual experiment carried out by the marketing team of the largest Serbian IT system integrator company, through the use of a proprietary commercial software ClickDimensions 
(of the so-named company), the results came out quite interesting. The experiment itself was aimed at a select number of B2B leads, namely representatives of financial institutions that some contact was already established with and that would be qualified as early-warm leads by the company's sales department.

The benefits of automated CRM solution are numerous, starting from the better time management to a more accessible qualified workforce to set, monitor and maintain the system is not obliged by formal education, as expressed in the underwhelming offering of specialize formal education in this filed globally [11].

Additionally, the connection between the employee engagement and self-regulated learning seems to be strong, which is obviously beneficial to the companies deploying a CRM solution [12]. A CRM solution such as the ClickDimension lands onto the architecture of MS Dynamics, understanding that an organization would use a single ERP platform to manage its resources across its different business functions.

One of the campaign flow's steps was as an automated email to the targeted group that would lead to a topic-specific blog post, which would contain a fairly simple fill-in for to opt in for further information on the topic. This step of the flow is a usual engagement of a direct, targeted communication channel that intends to establish direct communication to a member of a particular targeted group. Email itself is known to be a primarily one-way channel in marketing communication, so in order to make it a returnchannel that could provide some behavioral inputs for the analytics, the email itself had a strong call-to-action.

Below are some of the outcomes of the automated email campaign carried out as a flow-step in a particular campaign for a software solution for financial institution, as a pre-sales support campaign.

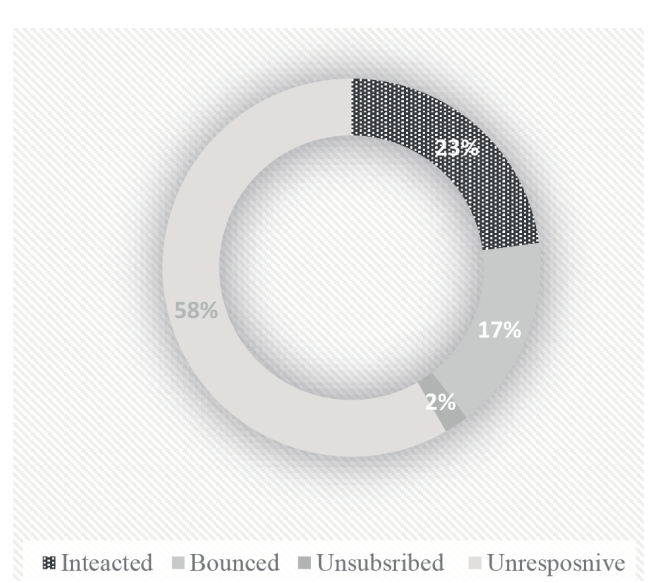

Graph 1. Conversion results of an automated email campaign
Interestingly, through the warm-leads automated email campaign, which is not known as the most effective conversion-focused channels in the digital marketing tools, we can see that the conversion rate was actually extremely high at $23 \%$ of the total number of responses.

Some alternative methods, such as social media targeting and retargeting would have a far less effective outcomes, with reasonably good conversions ranging from 3-5\% of total outreach.

\section{Lead scoring modeling based on iterative campaign management}

Although the modeling for particular lead-scoring would vary from one market situation to another, the underlining idea is that a model that would reflect organizational values and long-term goals is applicable as foundation to the later-evolving, situation-specific models that would come out of CRM's lead scoring [13].

Obviously the core architecture of a marketing campaign depends on the contextual market conditions, inclusive of the given product characteristics, targeted audience's preferences, competitor's recourses, planned level of marketing investments, and many other contributing factors.

The experience of establishing a lead-scoring model from a particular campaign, a conclusion has been made that he following campaign flow gave results better than anticipated:

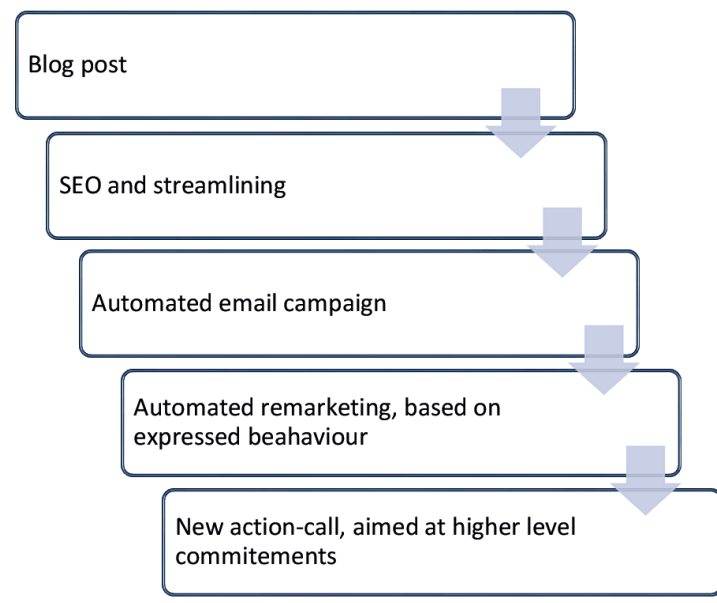

Graph 2. A particular digital campaign flow 
The first step of the campaign was to produce the initial content, a blog post, that was aimed at providing some valuable information to the targeted readers and at the same time serve the campaign as the early traffic driver. The attributed score for the lead-scoring at this first step of the flow was at about $20 \%$, as the selection metric was fairly wide.

A proven way to begin assessing the digital marketing opportunities would start with SEO as a service. SEO has a dominant role in the digital promotion strategy, since it influences the positioning of digital channels available to an organization such as: web sites, blogs, social network accounts, etc. So, web pages can be optimized to become "the most attractive" for the search engines in order to be first displayed when searches are performed using browsers [14]. The attributed score for the lead-scoring at this first step of the flow was much higher - at 35\%.

If the blog content and platform and the SEO criterion turned out to be success, the later stages of the campaign can afford the lower lead scoring as the quality of the lead-pool should have been heavily refined by now. In other words, the new, retargeted leads are now much more likely to lead to conversions. Therefore, the remaining 45 points are distributed as of $15-25-5$, respectively.

\section{CONCLUSIONS}

The author of this paper does by any means advocate that the processes automation should in a way substitute for the existence of marketing teams; furthermore, the main argument is that the marketing-native teams should devote their time to the more critical processes that required their expertise, rather than focusing on highly repetitive routine-based tasks.

Establishing modeled lead-scoring through configuring the CRM's tools could likely lead to the overall business optimization. The benefits of establishing a good model are apparent in the facts that it requires only informal/practical education, relies on organization-wide knowledge of processes and information rather than the marketing-specific expertise, and is fairly easily quantifiable and measurable - nearly in real-time.

These conclusions drawn from the paper analyses direct towards a modeled solution that that would be highly applicable in companies that already have in use a CRM such as Microsoft Dynamics, Oracle BI or some other similar solution. however, the author assumes that the proposed methodology could possibly be applicable to other brand's CRM solutions as well, given some necessary adjustments.

\section{REFERENCES}

[1]. M. K. Watfa, M. K., Najafi, N. and N. Bakkar,, "Targeted Online Marketing using Social Networking", International Journal of Online Marketing, 3, no. 3, pp. 37-50, 2013

[2]. E. Kulcsar, T. Sandor, "In The Maze Of E-Commerce. Online Trade Defining Variables In Romania." Management \& Marketing Journal 15.1, ppg. 126, 2017

[3]. M. Nuseir, "Digital Media Impact on SME Performance in the UAE", Academy of Entrepreneurship Journal, Volume 24, issue 1, 1528-2686-24-1-134, ppg. 3, 2018

[4]. D., Zajac, "Dropshipping as Logistics Business Model of e-Commerce", Logistyka, 4, 5069-5074, page 371, 2014

[5]. J. M. Anton, M. Hoeck,. "E-Business Customer Service", The Anton Press Santa Monica, 2002 retrieved from: https://www.researchgate.net/ publication/220007771_Customer_Relationship_ Management_a_strategy_to_sustain_the_organization's_name_and_products_in_the_customers'_ minds on Apr 08, 2019

[6]. N. M. Tichy, M.L. Tushman, C. Fombrun, "Social network analysis for organizations. Academy of Management Review”, 4(4), 507-519, 1979

[7]. C. Mathwick, C. Wiertz, K.Ruyter, "Social capital production in a virtual community." Journal of Consumer Research, 34(6), ppg. 832-849, 2008

[8]. J. Cox, "Strategic Marketing Workflow Examples for High Conversions" SendinBlue CRM Blogspace for Customer Dialogue, 2018, retrieved from https://blog.sendinblue.com/8-marketing-automation-workflow-examples-for-2017/ on March 28, 2019

[9]. Ž. Radosavljević, M. Radisavljević, A. Anđelković, „The Necessities of Eliminating Classical Concepts and Introduction of New Concepts into Strategic Management and Business" Ekonomika, Vol. 61, Jan-Mar 2015, ppg. 34-27, 2015

[10]. V. Jarvinen, H. Taiminen, "Harnesting Marketing Automation for B2B Content Marketing", Industrial Marketing Management, Volume 54, Elsavier, ppg. 116, 2016

[11]. A. M. Shaltoni, "E-marketing Education in Transition: An Analysis of International Courses and Programs", The International Journal of Management Education, Vol. 14 (2), ppg. 212-218, 2016 
[12]. D. S. Ackerman, B. L. Gross, \& K. Sawhney Celly, "Having Many Choice Options Seems Like a Great Idea, But... Student Perceptions About the Level of Choice for a Project Topic in a Marketing Course", Journal of Marketing Education, Vol. 36 (3), pp. 221-232, 2014
[13]. Alle V., "Reconfiguring the value Network", Journal of Business Strategy, Vol 21, pp. 37, 2000

[14]. L. Patrutiu-Baltes, "Inbound Marketing-the most important digital marketing strategy" Bulletin of the Transilvania University of Brasov. Economic Sciences. Series V, 9(2), ppg. 64, 2016 